\title{
Dyadic Interaction: The Effects of Controlling and Critical Behavior versus Warm and Responsive Behavior on Participant Behavior and Emotional Response
}

Joanna T. Prout

West Virginia University

Follow this and additional works at: https://researchrepository.wvu.edu/etd

\section{Recommended Citation}

Prout, Joanna T., "Dyadic Interaction: The Effects of Controlling and Critical Behavior versus Warm and Responsive Behavior on Participant Behavior and Emotional Response" (2011). Graduate Theses, Dissertations, and Problem Reports. 3435.

https://researchrepository.wvu.edu/etd/3435

This Thesis is protected by copyright and/or related rights. It has been brought to you by the The Research Repository @ WVU with permission from the rights-holder(s). You are free to use this Thesis in any way that is permitted by the copyright and related rights legislation that applies to your use. For other uses you must obtain permission from the rights-holder(s) directly, unless additional rights are indicated by a Creative Commons license in the record and/ or on the work itself. This Thesis has been accepted for inclusion in WVU Graduate Theses, Dissertations, and Problem Reports collection by an authorized administrator of The Research Repository @ WVU. For more information, please contact researchrepository@mail.wvu.edu. 
Dyadic Interaction: The Effects of Controlling and Critical Behavior versus Warm and Responsive Behavior on Participant Behavior and Emotional Response

Joanna T. Prout, MSW

Thesis submitted to the Eberly College of Arts and Sciences

at West Virginia University in partial fulfillment of the requirements

for the degree of

Master of Science

in

Psychology

Tracy L. Morris, Ph.D., Chair

Cheryl B. McNeil, Ph.D.

Michael Perone, Ph.D.

Department of Psychology

Morgantown, West Virginia 


\begin{abstract}
Dyadic Interaction: The Effects of Controlling and Critical Behavior versus Warm and Responsive Behavior on Participant Behavior and Emotional Response
\end{abstract}

\title{
Joanna T. Prout
}

Previous research has identified parental rejection and control as important factors in the development of childhood anxiety. However, information about the relationship between these constructs and child outcomes has been limited by ambiguous definition and difficulty in performing experimental manipulations. This study attempted to address these issues by examining self-reported anxiety and anxious behavior in 47 college undergraduates who interacted with either a warm- responsive partner or a critical-controlling partner during an origami task. Results showed that participant condition significantly impacted self report of anxiety-distress, anger-frustration, liking for partner, and desire to see partner again. Participants who interacted with a critical-controlling partner also engaged in higher rates of self-criticism and were less likely to respond to their partner or praise the dyad than participants who interacted with a warm-responsive partner. These findings lend support to parental behavior as an important factor in establishing and maintaining patterns of anxious responding in children. 


\section{TABLE OF CONTENTS}

TITLE PAGE

ABSTRACT

ii

TABLE OF CONTENTS

iii

LIST OF TABLES

iv

INTRODUCTION

1

PARENTING AND CHILD ANXIETY 1

LEARNING AND CHILD ANXIETY 2

$\begin{array}{ll}\text { CHILDHOOD SOCIAL ANXIETY } & 7\end{array}$

$\begin{array}{lr}\text { HYPOTHESES } & 9\end{array}$

METHOD

PARTICIPANTS

MEASURES

11

PROCEDURES

13

RESULTS

DISCUSSION

FINDINGS

LIMITATIONS

IMPLICATIONS AND FUTURE DIRECTIONS 20

REFERENCES

TABLES 


\section{List of Tables}

Table 1: Mean Confederate Behaviors by Condition 30

Table 2: Mean Post-task Questionnaire Ratings by Participant Condition 31

Table 3: Correlation Coeffecients for Post-task Questionnaire Ratings 32

Table 4: Follow-up Univariate Analyses of Variance for Post-task 33

Questionnaire

Table 5: Mean Observer Behavior Ratings By Participant Condition 34

Table 6: Correlation Coefficients for Observer Behavior Ratings 35

Table 7: Follow-up Univariate Analyses of Variance for Observer Ratings 36 of Participant Behaviors 
Dyadic Interaction: The Effects of Controlling and Critical Behavior versus Warm and Responsive Behavior on Participant Behavior and Emotional Response

A vast literature has examined the relationship between parental rejection and control and childhood anxiety (Rapee, 1997; DiBartolo \& Helt, 2007; McLeod, Wood, \& Weisz, 2007). Parental rejection has been defined as low levels of warmth and responsiveness during interactions with children (Clark \& Ladd, 2000). Parents high in rejection may frequently criticize or ignore their child. Parental control has been defined as intrusive parental involvement in children's activities and experiences and attempts to control children's thoughts and feelings (Barber, 1996). Highly controlling parents may insist on maintaining a developmentally-inappropriate level of involvement in the child's daily routine or frequently instruct the child that certain feelings are incorrect. Parental rejection and control typically are considered as two independent dimensions, with levels of each combining to form an overall parenting style (Baumrind, 1966).

Early studies of anxious adults' retrospective reports of their parents' behaviors indicated the possible importance of these two constructs (for review see Gerlsma, Emmelkamp, \& Arrindell, 1990); however, the results of this research may have been influenced by the current mood of the participant (Gillham, Putter, \& Kash, 2007) or memory biases (Hardt \& Rutter, 2004). Building on these findings, research moved to concurrent measurement of parent behaviors and child anxiety in both anxious and non-anxious parents and children (for reviews see Wood, McLeod, Sigmam, Hwang, \& Chu, 2003; Masia \& Morris, 1998). Although these studies have the advantage of measuring current behavior, their non-experimental nature limits the conclusions that can be drawn. To address this deficit, preliminary research assessing the 
effects of experimentally manipulated parental behavior on child anxiety is beginning to emerge (de Wilde \& Rapee, 2008).

Despite the large body of work that has been conducted concerning the constructs of rejection and control, evidence for specific links between parenting behaviors and child anxiety remains only tentative. In a recent meta-analysis, McLeod and colleagues (2007) found that parenting accounted for only $4 \%$ of the variance in predicting the presence of childhood anxiety disorders. The relationship between parenting behaviors and childhood anxiety is obscured due to methodological differences between studies, as well as ambiguous definitions of anxiety, parenting style, and parenting behaviors (Masia \& Morris, 1998).

Although early studies (Arrindell, Emmelkamp, Monsma, \& Brilman, 1983; Arrindell, Kwee, Methorst, van der Ende, Pol, \& Moritz, 1989 ) and more recent research (Rapee \& Melville, 1997) indicated the possibility that parenting behaviors might be specific risk factors for certain anxiety disorders, such as social anxiety disorder, most recent research has focused on using levels of parental control and rejection to differentiate groups of children with various anxiety disorders from groups of children free from psychiatric disorder (Siqueland, Kendall, \& Steinberg, 1996; Moore, Whaley, \& Sigman, 2004), or to differentiate anxious children from children with behavioral disruptions (Hudson \& Rapee, 2001; Dumas \& LaFreniere, 1993; Dumas, Serketich, \& LaFreniere, 1995). This preliminary study will attempt to address this deficit by comparing the effects of a critical and controlling partner versus a warm and responsive partner on participant post-task ratings of fear of negative evaluation, anxiety and distress, and anger and frustration. Also, observers will code specific participant behaviors during the task and provide global impressions of the participant.

\section{Learning Theory and Anxiety}


Recent renewal of interest in the application of learning theory to the development of anxiety (Mineka \& Zinbarg, 2006) encourages the examination of dyadic behavioral patterns in order to clarify the mechanisms through which parents may initiate and maintain anxious behavior in children. Parents of anxious children may be more likely to perform specific behaviors that indicate rejection (e.g., making critical comments) or control (e.g., taking over a task the child was working on). Over time, these parenting behaviors become an important part of the learning history that will function as the child's basis for dealing with novel interpersonal interactions and situations. A learning history that builds expectancies of rejection and lack of control may contribute to anxiety-related behaviors (e.g., withdrawal) when the child encounters unfamiliar situations (Ollendick, Vasey, \& King, 2001).

\section{Methodologies Examining Parenting and Childhood Anxiety}

Adult Retrospective Reports. A meta-analysis of adult retrospective reports of perceived parenting behavior by Gerlsma, Emmelkamp, and Arrindell (1990) concluded that participants with anxiety disorders, when compared to control participants, viewed their parents' behavior as less affectionate and more controlling. Arrindell and colleagues performed two studies aimed at differentiating types of anxiety disorders using the EMBU (Egna Minnen Betraffande Uppfostran or "My memories of upbringing;" Perris et al., 1980), a self-report measure that taps the parenting dimensions of rejection, over-protection, and warmth. An initial study (Arrindell et al., 1983) of outpatients using the EMBU found that when compared to control participants, participants with social anxiety disorder reported both parents to be low in emotional warmth and care and high in rejection and overprotection, participants with agoraphobia reported both parents to be low in warmth and mothers only to be high in rejection, and participants with a specific phobia of heights reported both parents to be low in warmth and high on rejection and 
overprotection. A similar later study using inpatients' reports on the EMBU as compared to controls' reports (Arrindell et al., 1989), found that participants with social anxiety disorder rated both parents as being more rejecting, overprotective, and lower in warmth, and participants with agoraphobia rated both parents as lower in warmth and mothers only as more rejecting. In both studies, the authors point out that although participants with social anxiety disorder were more likely than controls to rate their parents as overprotective, this pattern was not seen in participants with agoraphobia, suggesting a differential relationship between parenting factors and type of anxiety disorder.

Research by Parker using the Parental Bonding Instrument (PBI; Parker, Tupling, \& Brown, 1979), a self-report measure tapping the parenting dimensions of care and overprotection, has also indicated a relationship between retrospective reports of low parental care and high parental overprotection and heightened anxiety. In an early study of the relationship between PBI scores and trait anxiety and depression in a large non-clinical group, Parker found that low maternal care was associated with higher anxiety and depression scores, whereas high maternal overprotection was only associated with higher anxiety scores (Parker, 1979). A later study comparing the PBI scores of participants with and without anxiety disorders also found that anxious participants rated their parents as less caring and more overprotective than controls did (Parker, 1981). More recent research using the PBI (Anhalt \& Morris, 2008) found that participants with high levels of social anxiety were more likely to classify their mothers as using an affectionless control parenting style (low warmth and high control) and their fathers as using a either an affectionless control or affectionate constraint (high warmth and high control) parenting style. 
Concurrent Measurement of Parenting and Child Anxiety. With initial data indicating that parental rejection and control might be important contributors to the development of childhood anxiety, research moved to concurrent measurement of the relationship between these factors and anxiety in children. Krohne and Hock (1991) observed the interactions of mothers of anxious and non-anxious children as they worked on a problem-solving task. For female children only, mothers in the anxious group were more likely than mothers in the non-anxious group to give unsolicited help and to control the problem solving process. A later study by Siqueland, Kendall, and Steinberg (1996) found that parents of anxious children were rated as significantly more controlling than parents of non-anxious children during an interaction task, and that self-report measures revealed that anxious children rated their parents as significantly more rejecting than non-anxious children did.

Research also has examined the impact of parental anxiety disorders on rejection and control during parent-child interactions. An observational study comparing the interactions of mothers with and without anxiety disorders and their children found that anxious mothers were less warm and more controlling and critical than non-anxious mothers (Whaley, Pinto, \& Sigman, 1999). Child anxiety also was assessed and found to be most associated with control during interactions, whereas maternal anxiety was most associated with warmth during interactions. An extension of this research using a similar observational task with a four-group design involving mother-child dyads with either one, both, or neither member of the dyad diagnosed with an anxiety disorder found that mothers displayed less warmth and more control toward anxious children, regardless of their own anxiety status (Moore, Whaley, \& Sigman, 2004). The authors interpret these results as supporting an interactional model of the 
development and maintenance of childhood anxiety, with children's responses actively shaping their parents' behaviors.

Other observational studies have examined the specificity of the relationship between maternal control and rejection and childhood anxiety versus behavioral disruptions. Hudson and Rapee (2001) used observational ratings of rejection and control in mother-child dyads including children with an anxiety disorder, children with oppositional defiant disorder, and children with no psychiatric disorder. Results showed that both mothers of anxious and oppositional children displayed elevated levels of control when compared to mothers of nonclinical children, whereas only mothers of anxious children were more negative than control mothers during interactions. Dumas and LaFreniere (1993) compared the interactions of mothers and preschool children rated as socially competent, average, anxious, or aggressive during a puzzle problem-solving task. In a novel design, children interacted with both their own and an unfamiliar mother. High levels of positivity and reciprocity were found in the interactions of mothers of competent and average children during interactions with both their own and unfamiliar children, whereas mothers of anxious children demonstrated this pattern only when interacting with an unfamiliar child. Mothers of anxious children were found to respond to their children with a consistently high level of negativity. Also, in contrast to the competent and average children, anxious children were more likely to ignore or reject the positive overtures of an unfamiliar mother. In a similar later study (Dumas et al., 1995) focusing on patterns of control between mother and child, mothers and competent children were found to engage in positive exchanges with low levels of coercion. In contrast, mothers of anxious children had highly aversive interactions, with both members of the dyad using coercive attempts at control, with mothers likely to ignore demands and children likely to resist demands. 
These studies highlight the importance of considering the transactional nature of parent-child interactions in the development and maintenance of maladaptive child behaviors such as anxiety.

\section{Childhood Social Anxiety}

Anxiety may be particularly detrimental to children's social functioning, where behaviors such as avoidance and withdrawal may lead to missed opportunities to gain important social skills (Rubin \& Burgess, 2001). Research shows that children with high levels of social anxiety show lower competence in social and emotional functioning (Ginsburg, La Greca, \& Silverman, 1998) and are more likely to be rejected by peers (Inderbitzen, Walters, \& Bukowski, 1997). Child social anxiety may progress to social anxiety disorder, a common and potentially debilitating condition that is just beginning to receive adequate research attention (for reviews see Kashdan \& Herbert, 2001; Ollendick \& Hirshfeld-Becker, 2002). Social anxiety disorder in children and adolescents has been found to be related to impaired social skills, depressed mood, loneliness, and diagnoses of other psychiatric disorders (Beidel, Turner, \& Morris, 1999; Beidel et al., 2007), as well as increased rates of substance abuse (DeWit, MacDonald, \& Offord, 1999).

Although it is generally accepted that maladaptive anxiety in children stems from the combination of various biological and social factors (Morris, 2001; Elizabeth et al., 2006), the parent-child relationship has been implicated as an important early contributor to the development of child anxiety and therefore warrants further research (Morris, 2004). Most observational research examining parent-child interactions has focused on children with behavioral disorders (Patterson, 1982; Reid, 1978). Using adaptations of these researchers' methods, Morris and colleagues have examined the nature of parent-child relationships in 
children with heightened social anxiety. An observational study of mothers and children with high and low levels of social anxiety found that mothers of high anxious children predicted that their children would use more avoidant or aggressive solutions to problem scenarios than mothers of low anxious children (Spaulding \& Morris, 1997). In a more recent study, Greco and Morris (2002) found that the fathers of children rated as high in social anxiety were more controlling during an origami task than fathers of children rated as low in social anxiety.

In an observational study involving child, mother, and father triads, two or three family groups were brought together in the laboratory (Rork \& Morris, 2009). Children were instructed to work together to create a skit to present to their parents and two researchers. Observational and self-report data showed that mother and father overprotective behavior was positively associated with higher levels of child social anxiety.

The current study attempted to further the results of this research by using a design that experimentally manipulates critical-controlling and warm-responsive behaviors in order to determine their effect on participants' social anxiety and interaction behavior. College student participants were divided into two groups, one in which a confederate member of the research team performed critical and controlling behaviors and one in which the confederate member performed warm and responsive behaviors. Observers coded participant behavior during the interaction and also provided global ratings of their overall impression of the participant during the task. In addition, participants provided ratings of their own fear of negative evaluation, anxiety-distress, and anger-frustration immediately following the interaction. Performance of this initial experiment using college students allowed for the evaluation of the relevance of the variables of control, criticism, and warmth-responsiveness in a controlled laboratory study measuring participant behavior and emotional response. 
The following hypotheses were proposed:

\section{Participant Self-Report}

$\mathrm{H}$ 1. Participants in the critical-controlling confederate group will endorse higher levels of fear of negative evaluation on the Post-task Questionnaire than will participants in the warm-responsive confederate group.

H 2. Participants in the critical-controlling confederate group will report higher levels of anxiety-distress on the Post-task Questionnaire than will participants in the warmresponsive confederate group.

H 3. Participants in the critical-controlling confederate group will report higher levels of anger-frustration on the Post-task Questionnaire than will participants in the warmresponsive confederate group.

H 4. Participants in the critical-controlling confederate group will rate themselves as less likely to want to work with their dyad partners again on the Post-task Questionnaire than will participants in the warm-responsive confederate group.

\section{Observer Global Ratings}

H 5. Observer ratings of anxiety-distress will be higher for participants in the criticalcontrolling confederate group than for participants in the warm-responsive confederate group.

H 6. Observer ratings of anger-frustration will be higher for participants in the criticalcontrolling confederate group than for participants in the warm-responsive confederate group.

H 7. Social Phobia and Anxiety Inventory (SPAI) scores will be inversely related to observer ratings of interpersonal skill during the interaction task. 
H 8. SPAI scores will be directly related to observer and participant ratings of anxietydistress during the interaction task.

\section{Observer Specific Behavioral Ratings}

H 9. Participants in the critical-controlling confederate group will engage in higher rates of the following behaviors than will participants in the warm-responsive confederate group: withdrawal from task, criticism of self, dyad, or confederate, and ignore confederate. See Appendix A for definitions of participant behavioral codes.

H 10. Participants in the critical-controlling confederate group will engage in lower rates of the following behaviors than will participants in the warm-responsive confederate group: respond positively to confederate, encouragement, and praise of self, dyad, or confederate.

For descriptive and exploratory purposes, data were obtained for several additional behavioral codes (e.g., verbal interruption, physical takeover of task, positive and negative commands, nervous and appropriate laughter, and speech not otherwise coded) but no hypotheses were extended regarding group differences.

\section{Method}

\section{Participants}

Video and questionnaire data were collected for a total of 50 undergraduate students (36 female, 14 male) at West Virginia University, Morgantown, WV who participated in the experiment in exchange for extra credit in a psychology course. Three participants were excluded from data analyses, one due to a prior relationship with the confederate, one due to being outside the age range of the study, and one due to video equipment failure. The 47 remaining participants ranged in age from 18 to 23 years $(M=19.85, S D=1.08)$ and were comprised of 14 males and 
33 females. Most participants were sophomores (38\%) or juniors (38\%) with some seniors $(6 \%)$ and freshman (17\%) also included. The sample identified primarily as Caucasian (89\%), with a few participants selecting African-American (2\%), Asian-American (4\%), Multiple Races (2\%), or Other $(2 \%)$ for their race.

Measures

Demographic Questionnaire (see Appendix B). Participants completed a brief demographic questionnaire concerning their age, year in school (freshman, sophomore, etc.), race, ethnicity, and gender.

Social Phobia and Anxiety Inventory (SPAI). The SPAI (Turner, Beidel, Dancu, \& Stanley, 1989) is a self-report questionnaire measuring behavioral, cognitive, and physiological symptoms of anxiety in a variety of potentially fear-producing social situations (e.g., encounters with strangers, members of the opposite sex, group situations) using a 7-point Likert scale. An additional 13 items measuring anxiety symptoms specific to agoraphobia is included in the SPAI to facilitate differentiation between anxiety related to fear of negative evaluation by others, indicative of social anxiety disorder, and anxiety related to fear of having panic attacks, indicative of agoraphobia. Final scores on the SPAI are calculated by subtracting the score on the agoraphobia subscale from the score on the social anxiety disorder subscale. Research using an undergraduate sample has shown the SPAI to have high overall and subscale internal consistency and high convergent validity with other measures of social anxiety (Osman, Barrios, Aukes, \& Osman, 1995).

Post-task Questionnaire (see Appendix C). Immediately following the interaction, participants provided global ratings of their own fear of negative evaluation, anxiety-discomfort, and anger-frustration during the task on a Likert scale ranging from 1-5, with 1 indicating "not at 
all" and 5 indicating "extremely." Participants also rated how much they liked their dyad partner and would like to interact with their dyad partner again in a variety of situations, including work and social environments, on similar 5-point Likert scales.

Coding System. The coding system used for behavioral ratings of both the participant (see Appendix A) and confederate (see Appendix D) was adapted from prior coding systems used by Morris and colleagues (Spaulding \& Morris, 1997; Greco \& Morris, 2002; Rork \& Morris, 2009). Confederates in the controlling-critical group were trained to engage in the following behaviors: criticism directed toward participant, negatively-stated command, verbal interruption, physical takeover of task, and ignoring participant statements. Confederates in the warmresponsive group were trained to engage in the following behaviors: praising participant, praising dyad, encouragement, and laughing appropriately. A minimum frequency of each confederate behavior was required to be performed during the 10-minute interaction. In addition, confederates were trained not to perform behaviors characteristic of the alternate condition.

Confederate training involved the investigator providing confederates with detailed explanations and examples of the types of behaviors to be performed. Confederates then role played both the critical-controlling and warm-responsive role with research team members until they were consistently able to meet the minimum frequencies of each behavior. An observer performed integrity checks by rating confederate behavior for $20 \%$ of interactions to ensure that confederates maintained the expected threshold of targeted behaviors for the assigned condition and did not engage in behaviors characteristic of the other condition.

Observers coded the number of occurrences of the following participant behaviors: criticism of self, dyad, or confederate; verbal interruption of confederate; physical takeover of task; negative command; positive command; ignore confederate statement; withdrawal from 
task; nervous laughter; speech not otherwise coded; responds positively to confederate; encouragement; appropriate laughter; and praise of self, dyad, or confederate. Observers also provided the following global ratings on a 5-point scale reflecting an overall impression of the participant during the task: anxiety-distress, $1=$ "very relaxed" and $5=$ "very anxiousdistressed;" anger-frustration, $1=$ "very relaxed" and 5 = "very angry-frustrated;" and interpersonal skill, $1=$ "very low level of skill" and $5=$ "very high level of skill."

Coder training involved observers and the primary coder viewing and coding videotapes of interactions. The primary coder then reviewed the observer's codes and discussed any discrepancies. This process continued until coders reached a high level of agreement (approximately 80\%) with the primary coder on ratings of all behaviors.

\section{Procedure}

Participants were recruited and scheduled for appointments via an online system that describes research studies in which psychology undergraduate students can participate in order to earn extra credit. Specific appointment times were posted for male and female participants. One male and one female confederate were trained to perform both the critical-controlling and warmresponsive role. Participants were assigned to one of two groups: (a) confederate engages in high rates of criticism-control or (b) confederate engages in low rates of criticism-control and high rates of warm-responsive behavior. To maintain gender balance, the first participant of each gender was assigned by coin flip to a condition, with the second participant of that gender assigned to the alternate condition. This pattern of assignment to group continued for both genders until recruitment was completed for the study.

At the appointment, the participant was brought into the lab where an investigator obtained informed consent before the initiation of any procedures. Participants were told that 
they were being asked to participate in a cooperative learning task involving assembling origami figures with another undergraduate student, who had already arrived and completed the consent form, and that their interaction would be videotaped. First, the investigator explained the SPAI and Demographic Questionnaire to the participant, who then completed the measures alone. After completion of the questionnaires, the investigator and participant moved into a separate room with the confederate, and the experimenter explained the origami task in more detail. The dyad was instructed that they were to work together for 10 minutes to create origami figures using the instructions and paper on the table. Instructions for several figures were presented, and the dyad was told that if they completed the first figure, they could move on to additional figures (see Appendix E). The dyad was instructed to begin the task as soon as the investigator left the room. After 10 minutes had passed, the investigator returned to the room and led the participant to a separate room to complete the post-task questionnaire. After the collection of study data had ended, all participants were sent an email explaining that the individual they completed the origami figures with was a member of the research team and outlining the study hypotheses and purposes of this manipulation.

Results

Preliminary Analyses. The critical-controlling condition included 25 participants (18 female, 7 male) and the warm-responsive confederate condition included 22 participants (15 female, 7 male). As three female participants completed the origami task with the male confederate, multivariate analysis of variance (MANOVA) was conducted to compare outcome data from mixed-gender dyads with data from same-gender dyads. These analyses revealed that mixed-gender dyads did not differ significantly from same-gender dyads in post-task questionnaire scores $F(6,42)=0.07$, observer behavioral codes $F(7,39)=0.75$, or observer 
global ratings, $F(3,43)=1.78$. However, the very small size of the mixed-gender group may have significantly limited the power to detect any between-group differences.

Analyses were conducted to determine if significant gender differences were evident for participants' SPAI scores, post-task questionnaire scores, observer global codes, and observer behavioral codes. Independent samples t-tests showed no significant differences between males' $(M=31.41, S D=23.56)$ and females' $(M=38.57, S D=25.25)$ scores on the SPAI, $t(45)=.91$. MANOVA revealed no between-gender differences in participants' post-task questionnaire scores, $F(6,40)=.91$, observer global codes, $F(3,43)=.98$, or observer behavioral codes, $F(7$, $39)=1.50$.

Independent-samples t-tests showed no significant differences between the ages of participants assigned to the warm-responsive condition $(M=20.05, S D=1.13)$ and participants assigned to the critical-controlling condition $(M=19.68, S D=1.03), t(45)=-1.16$. Conditions were also found not to significantly differ by gender, $t(45)=-.28$, or mean SPAI score, $t(45)=-$ .22 .

A manipulation check was performed through observer coding of confederate behaviors during ten randomly-selected interactions (5 warm-responsive, 5 critical-controlling). Criticism of participant, negative commands, interruption, ignoring, and physical takeover of origami materials occurred at higher rates during the critical-controlling condition and generally did not occur during the warm-responsive condition. Further, praise of participant, praise of dyad, encouragement, and appropriate laughter occurred at higher rates during the warm-responsive condition and generally did not occur during the critical-controlling condition. Mean rates of each confederate behavior by condition can be found in Table 1 . 
Observation of participant behaviors showed no instances of participant criticism of the confederate and only one instance each of participants praising self or encouraging. Therefore, these codes were not considered in further analyses. Inter-observer agreement on participant behavioral codes was calculated by having two undergraduate students code a total of eight interactions and ranged by code from $92 \%$ to $97 \%$ agreement. Inter-observer agreement on global codes was calculated using Spearman's correlation coefficient. Observer ratings of participant anger-frustration were found to be significantly correlated, $\rho=.80$. However, between-observer ratings of participant anxiety-distress, $\rho=.44$, and interpersonal skill level, $\rho=$ .36 , were not significantly correlated.

\section{Hypotheses}

Participant Self-report. Initial analyses examined the impact of condition on participants' post-task questionnaire ratings. Descriptive statistics of participants' ratings on the post-task questionnaire are shown in Table 2. Post-task ratings of anxiety-distress, anger-frustration, and feeling judged were positively correlated (see Table 3). Similarly, post-task ratings of liking for partner and desire to see partner again in a social or work situation were positively correlated. Further, post-task ratings of anxiety, frustration, and feelings of judgment during the task were negatively correlated with liking for partner and desire to see partner again.

To test whether participant condition impacted post-task questionnaire responses, MANOVA including participant condition (critical-controlling or warm-responsive partner) as the independent variable and post-task questionnaire ratings as dependent variables was conducted. With the use of the Wilk's Lambda criterion, post-task questionnaire ratings were found to be significantly impacted by participant condition, $F(6,40)=11.51, p<.001$. As shown in Table 4, follow-up univariate analyses revealed a significant effect of condition for 
each item on the post-task questionnaire, with participants who interacted with a criticalcontrolling confederate endorsing significantly higher levels of anxiety-distress, angerfrustration, and feelings of judgment and significantly lower levels of liking for partner or desire to interact with partner again when compared with participants who interacted with a warmresponsive confederate. Thus, hypotheses one through four were supported.

SPAI Scores. In partial support of hypothesis eight, a bivariate correlation showed a significant relationship between participants' scores on the SPAI and participants' self-report of anxiety during the task, $r(47)=0.46, p<.01$. However, participants' SPAI scores were found to have no significant correlation with observer global ratings of anxiety-distress, $r(47)=0.02$, or observer global ratings of interpersonal skill $r(47)=0.03$, thus hypothesis seven was not supported.

Observer Global Ratings. To test the association between observer global ratings and participant condition, MANOVA with participant condition as the independent variable and observer global ratings of anxiety-distress and anger-frustration as the dependent variables was conducted. This test showed no significant between-condition differences, $F(2,44)=2.20$ indicating that hypotheses five and six were not supported.

Observer Behavioral Ratings. Means and standard deviations for observer ratings of participant behavior by group can be found in Table 5. To examine whether observed participant behaviors varied by condition, MANOVA including condition as the independent variable and the observer behavioral codes of criticism of dyad, criticism of self, praise of dyad, praise of confederate, withdrawal, ignore, and respond positively to confederate as the dependent variables was conducted. This test showed a significant effect with the use of Wilk's criterion, $F(7,39)=$ $3.45, p<.01$. 
As shown in Table 7, follow-up univariate analyses showed that condition had a significant impact on rates of criticism of self, with participants in the critical-controlling condition being more likely to make self-critical statements than participants in the warmresponsive condition. A significant effect of condition was also present for praise of dyad and responding positively to the confederate, with participants in the warm-responsive condition being more likely to demonstrate these behaviors than participants in the critical-controlling condition. However, no significant effect of condition was found on criticism of dyad, praise of confederate, withdrawal, or ignoring confederate. These results give partial support to hypotheses nine and ten.

\section{Discussion}

A large body of research has examined how parental rejection and control impact child development; however, links between specific parenting behaviors and childhood anxiety remain only tentative (McLeod, Wood, \& Weisz, 2007). Research has been limited both by difficulties in conducting experimental manipulations of parent behavior and by abstract and inconsistent definitions of the constructs of rejection and control (Masia \& Morris, 1998). The current study attempted to add to the existing literature by examining if participants who interacted with a critical and controlling partner would report greater subjective anxiety and display higher rates anxious behavior when compared to participants who interacted with a warm and responsive partner.

\section{Findings}

Comparison of rates of confederate behavior during the critical-controlling and warmresponsive conditions indicated that the manipulation was successfully performed. Further, posttask questionnaire responses suggested that participants' experiences were consistent with their 
assigned condition, with members of the critical-controlling condition reporting higher levels of anxiety-distress, anger-frustration, and feeling judged, and lower levels of liking for partner and wanting to interact with partner again when compared to members of the warm-responsive condition. This finding supports the idea that different emotional states can be induced during even a brief interpersonal interaction.

Participants' self-reports of social anxiety, as measured by the SPAI, were significantly associated with self-reported anxiety during the task but not with observer global ratings of participant anxiety-distress or interpersonal skill. This finding is consistent with previous research that has suggested that measures relying on the same source are more likely to be in agreement than measures relying on different sources (Kenny, 1993). Further, the subjective experience of anxiety does not necessarily translate into overtly anxious behavior; participants who felt anxious during the task may not have appeared anxious or unskilled to an outside observer (Funder \& Dobroth, 1987).

No significant between-conditions differences were found in observer global ratings. This lack of distinction may be due in part to the limited range of behavior measured. Most participants did not appear overtly anxious or angry and therefore received ratings below the midpoint of the scale. Similarly, most participants demonstrated adequate interpersonal skill and fell around the midpoint of the scale. Observation of a greater number of participants or expansion of the rating scale might lead to better differentiation of global codes between conditions.

When the association between participant condition and observer ratings of participant behavior was examined, critical-controlling group members were found to show higher rates of self-criticism and lower rates of responding to the confederate or praising the dyad. This finding 
suggests that rejecting or controlling behaviors performed by one member of a dyad may impact the behaviors of the other member, even during a brief interaction. Confederates may have modeled behavior that participants then imitated (Bandura, 1962). More specifically, in the critical-controlling condition, the confederate's high rate of criticism of the participant may have led to increased participant self-criticism. In the warm-responsive condition, confederates' warm and encouraging responses to the participant may have increased the likelihood that participants would respond to the confederate's remarks. The higher rate of praise provided by the confederate in the warm-responsive condition may have also led to increased likelihood that the participant would make praise statements about the dyad.

\section{Limitations}

This study has several limitations. First, an interaction between two college students is undoubtedly dissimilar to an interaction between a parent and a child. However, as parents are thought to be a primary influence on children's development, the impact of rejecting or controlling parenting on child behavior may be even greater than the impact of confederate actions on participant behavior during this study. Also, as with many studies that focus on the occurrence of low rate behaviors, many dependent variables included in analyses had nonnormative distributions. This characteristic may have decreased the power of the parametric statistical tests used in the analyses.

Another limitation is the gender distribution of the study's sample, which included more female than male participants and focused on the interactions of same-gender dyads. Research has indicated that the gender of both partners may influence the nature of dyadic interactions, with women being more likely to focus on creating a sense of equality and men being more likely to use directive communication patterns (Carli \& Bukatko, 2000). There is also evidence 
that parent-child interaction may be influenced by both the gender of the parent and the gender of the child (McKee et al., 2007). Further research using larger and more varied samples is necessary to examine these associations.

\section{Implications and Future Directions}

The results of the current study indicate that exposure to critical and controlling behavior, even for a short period of time and during interaction with a peer, may lead to a subjective experience of anxiety and frustration as well as increased self-criticism and decreased responsiveness and praise. As children experience repeated daily interaction with parents who provide their primary source of support and guidance, parental critical and controlling behavior may lead to an even greater incidence of anxious child behavior. Children who behave in an anxious manner might elicit similarly critical and controlling reactions from others in the environment; therefore establishing patterns of interpersonal interaction that are conducive to continued anxiety.

Research that uses biologically-related dyads to examine the impact of parenting on child behavior is typically unable to partial out the relative contributions of genetics and environment to any observed effect. It has been hypothesized that research may often overstate the impact of the environment due to disregard of the influence of gene-environment correlations (Rutter, 2010). While genetic factors undoubtedly play a role in childhood anxiety, the fact that anxious behavior is developed and maintained within a particular environment cannot be disregarded. As this study involved the interaction of two non-related individuals, the observed effect that the critical-controlling condition displayed increased subjective anxiety, self-criticism, and decreased adaptive behavior such as responsiveness and praise when compared to the warmresponsive condition can be attributed to the behaviors of the confederate. 
Future research should continue to explore the relationship between specific critical or controlling parent behaviors and children's experience of anxiety. A potentially useful method to clarify this relationship would be to examine changes in child anxious behavior before and after an intervention that alters critical or controlling parent behaviors. As parent-child interaction patterns are often deeply entrenched, children may require repeated exposure to altered parent behavior before any change in their behavior becomes evident. However, treatments which change parent-child interaction patterns may be an important aspect of early interventions for disorders such as childhood anxiety. By increasing the adaptive qualities of this key early relationship, children may be better able to create and maintain the many future relationships necessary for successful development, therefore decreasing the risk for anxiety and other disorders. 


\section{References}

Anhalt, K. \& Morris, T.L. (2008). Parenting characteristics associated with anxiety and depression: Exploring the contribution of multiple factors. Journal of Early and Intensive Behavioral Intervention, 5, 122-137

Arrindell, W. A., Emmelkamp, P. M.G., Monsma, A., \& Brilman, E. (1983). The role of perceived parental rearing practices in the aetiology of phobic disorders: A controlled study. British Journal of Psychiatry, 143, 183-187.

Arrindell, W. A., Kwee, M. G. T., Methorst, G. J., Van der Ende, J., Pols, E., \& Moritz, B. J. M. (1989). Perceived parental rearing styles of agoraphobic and socially phobic inpatients. British Journal of Psychiatry, 155, 526-535.

Bandura, A. (1962). Social learning through imitation. Lincoln, NE: University of Nebraska Press.

Barber, B. K. (1996). Parental psychological control: Revisiting a neglected construct. Child Development, 67, 3296-3319.

Baumrind, D. (1966). Effects of authoritative control on child behavior. Child Development, 37, 887-907. doi:10.2307/1126611.

Beidel, D. C., Turner, S. M., Morris, T. L. (1999). The psychopathology of childhood social phobia. Journal of the American Academy of Child and Adolescent Psychiatry, 6, 643650.

Beidel, D. C., Turner, S. M., Young, B. J., Ammerman, R. T., Sallee, F. R., \& Crosby, L. (2007). Psychopathology of adolescent social phobia. Journal of Psychopathology and Behavioral Assessment, 29, 47-54.

Carli, L. L., \& Bukatko, D. (2000). Gender, communication, and social influence: A 
developmental perspective. In T. Eckes \& H. M. Trautner (Eds.), The developmental social psychology of gender (pp. 295-332). Mahwah, NJ: Erlbaum.

Clark, K., \& Ladd, G. (2000). Connectedness and autonomy support in parent-child relationships: Links to children's socioemotional orientation and peer relationships. Developmental Psychology, 36, 485-498. doi:10.1037/0012-1649.36.4.485

de Wilde, A., \& Rapee, R. M. (2008). Do controlling maternal behaviors increase state anxiety in children's responses to a social threat? A pilot study. Journal of Behavior Therapy and Experimental Psychiatry, 39, 526-537.

DeWit, D.J., MacDonald, K., \& Offord, D. R. (1999). Childhood stress and symptoms of drug dependence in adolescence and early adulthood: Social phobia as a mediator. American Journal of Orthopsychiatry, 69, 61-72.

DiBartolo, P. M., \& Helt, M. (2007). Theoretical models of affectionate versus affectionless control in anxious families: A critical examination based on observation of parent-child interactions. Clinical Child and Family Psychology, 10, 253-274.

Dumas, J. E., \& LaFreniere, P. J. (1993). Mother-child relationships as sources of support or stress: A comparison of competent, average, aggressive, and anxious dyads. Child Development, 64, 1732-1754.

Dumas, J. E., Serketich, W. J. \& LaFreniere, P. J. (1995). "Balance of power:” A transactional analysis of control in mother-child dyads involving socially competent, aggressive, and anxious children. Journal of Abnormal Psychology, 104, 104-113.

Elizabeth, J., King, N., Ollendick, T. H., Gullone, E., Tonge, B., Watson, S., \& MacDermott, S. (2006). Social anxiety disorder in children and youth: A research update on aetiological factors. Counseling Psychology Quarterly, 19, 151-163. 
Funder, D. C., \& Dobroth, K. M. (1987). Differences between traits: Properties associated with interjudge agreement. Journal of Personality and Social Psychology, 52, 409-418.

Gerlsma, C., Emmelkamp, P. M. G., \& Arrindell, W. A. (1990). Anxiety, depression, and perception of early parenting: A meta-analysis. Clinical Psychology Review, 10, 251-277.

Gillham, J. E., Putter, P., \& Kash, V. M. (2007). The effects of sad mood on reports of parents'caregiving behaviors. Journal of Psychopathology and Behavioral Assessment, 29, $125-133$.

Ginsburg, G. S., La Greca, A. M., \& Silverman, W. K. (1998). Social anxiety in children with anxiety disorders: Relation with social and emotional functioning. Journal of Abnormal Child Psychology, 26, 175-185.

Greco, L. A., \& Morris, T. L. (2002). Paternal child-rearing style and child social anxiety: Investigation of child perceptions and actual father behavior. Journal of Psychopathology and Behavioral Assessment, 24, 259-267.

Hardt, J. \& Rutter, J. (2004). Validity of adult retrospective reports of adverse childhood experiences: Review of the evidence. Journal of Child Psychology and Psychiatry, 45, $260-273$.

Hudson, J. L., \& Rapee, R. M. (2001). Parent-child interactions and anxiety disorders: An observational study. Behaviour Research and Therapy, 39, 1411-1427.

Kenny, D. A. (1993). A coming-of-age for research on interpersonal perception. Journal of Personality, 61, 789-807.

Inderbitzen, H. M., Walters, K.S., \& Bukowski, A. L. (1997). The role of social anxiety in adolescent peer relations: Differences among sociometric status groups and rejected subgroups. Journal of Clinical Child Psychology, 26, 338-348. 
Kashden, T. B., \& Herbert, J. D. (2001). Social anxiety disorder in childhood and adolescence: Current status and future directions. Clinical Child and Family Psychology Review, 4, 3761.

Krohne, H. W., \& Hock, M. (1991). Relationships between restrictive mother-child interactions and anxiety of the child. Anxiety Research, 4, 109-124.

La Greca, A. M., \& Lopez, N. (1998). Social anxiety among adolescents: Linkages with peer relationships and friendships. Journal of Abnormal Child Psychology, 26, 83-94.

Masia, C. L., \& Morris, T. L. (1998). Parental factors associated with social anxiety: Methodological limitations and suggestions for integrated behavioral research. Clinical Psychology: Science and Practice, 5, 211-228.

McKee, L., Roland, E., Coffelt, N., Olson, A., Forehand, R., Massari, C., et al. (2007). Harsh discipline and child problem behaviors: The roles of positive parenting and gender. Journal of Family Violence, 22(4), 187-196. doi:10.1007/s10896-007-9070-6.

McLeod, B. D., Wood, J. J., \& Weisz, J. R. (2007). Examining the association between parenting and childhood anxiety: A meta-analysis. Clinical Psychology Review, 27, 155-172

Mineka, S., \& Zinbarg, R. (2006). A contemporary learning theory perspective on the etiology of anxiety disorders: It's not what you thought it was. American Psychologist, 61, 10-26.

Moore, P. S., Whaley, S. E., \& Sigman, M. (2004). Interactions between mothers and children: Impacts of maternal and child anxiety. Journal of Abnormal Psychology, 113, 471-476.

Morris, T. L. (2001). Social phobia. In M. W. Vasey \& M. R. Dadds (Eds.), The developmental psychopathology of anxiety (pp. 435-458). New York: Oxford University Press.

Morris, T.L. (2004). Social development and context. In T.L. Morris, and J.S. March (Eds.), Anxiety disorders in children and adolescents (2nd ed, pp. 59-70). New York : Guilford. 
Mulac, A., Wiemann, J., Widenmann, S., \& Gibson, T. (1988). Male/Female language differences and effects in same-sex and mixed-sex dyads: The gender-linked language effect. Communication Monographs, 55(4), 315.

Ollendick, T. H., \& Hirshfeld-Becker, D. R. (2002). The developmental psychopathology of social anxiety disorder. Biological Psychiatry, 51, 144-158.

Ollendick, T. H., Vasey, M. W., \& King, N. J. (2001). Operant conditioning influences in childhood anxiety. In M. W. Vasey \& M. R. Dadds (Eds.), The developmental psychopathology of anxiety (pp. 231-252). New York: Oxford University Press.

Osman, A., Barrios, F. X., Aukes, A., \& Osman, J. R. (1995). Psychometric evaluation of the Social phobia and anxiety inventory in college students. Journal of Clinical Psychology, $51,235-243$.

Parker, G. (1979). Reported parental characteristics in relation to trait depression and anxiety levels in a non-clinical group. Australian and New Zealand Journal of Psychiatry,13, 260-264.

Parker, G. (1981). Parental representations of patients with anxiety neurosis. Acta Psychiatrica Scandinavica, 63, 33-36.

Parker, G., Tupling, H., \& Brown, L. B. (1979). A parental bonding instrument. British Journal of Medical Psychology, 52, 1-10.

Patterson, G. R. (1982). Coercive family process. Eugene, OR: Castalia.

Perris, C., Jacobsson, L., Lindstron, H., von Knorring, L., \& Perris, H. (1980). Development of a new inventory assessing memories of parental rearing behavior. Acta Psychiatry Scandinavia, 61, 163- 177. 
Rapee, R. M. (1997). Potential role of childrearing practices in the development of anxiety and depression. Clinical Psychology Review, 17, 47-67.

Rapee, R. M., \& Melville, L. F. (1997). Recall of family factors in social phobia and panic disorder: Comparison of mother and offspring reports. Depression and Anxiety, 5, 7-11.

Reid, J. B. (1978). A social learning approach to family intervention: Vol. 2. Observation in home settings. Eugene, OR: Castalia.

Rork, K., \& Morris, T. (2009). Influence of parenting factors on childhood social anxiety: Direct observation of parental warmth and control. Child \& Family Behavior Therapy, 31, 220235. doi:10.1080/07317100903099274.

Rubin, K. H., \& Burgess, K. B. (2001). Social withdrawal and anxiety. In M. W. Vasey \& M. R. Dadds (Eds.), The developmental psychopathology of anxiety (pp. 407-434). New York: Oxford University Press.

Rutter, M. (2010). Gene-environment interplay. Depression and Anxiety, 27(1), 1-4. doi:10.1002/da.20641.

Siqueland, L., Kendall, P. C., \& Steinberg, L. (1996). Anxiety in children: Perceived family environments and observed family interaction. Journal of Clinical Child Psychology, 25, $225-237$.

Spaulding, S. \& Morris, T.L. (1997, March). Direct observation of mother-child interaction: An etiological pathway for social anxiety. In C.L. Masia and T.L. Morris (Chairs), Assessment of anxiety disorders in youth: Innovative techniques for comprehensive assessments of anxiety symptomatology._Symposium presented at the annual meeting of the Anxiety Disorders Association of America, New Orleans. 
Turner, S. M., Beidel, D. C., Dancu, C. V., \& Stanley, M. A. (1989). An empirically derived inventory to measure social fears and anxiety: The social phobia and anxiety inventory. Psychological Assessment, 1, 35-40.

Whaley, S. E., Pinto, A., \& Sigman, M. (1999). Characterizing interactions between anxious mothers and their children. Journal of Consulting and Clinical Psychology, 67, 826-836.

Wood, J. J., McLeod, B. D., Sigman, M., Hwang, W. C., \& Chu, B. C. (2003). Parenting and childhood anxiety: theory, empirical findings, and future directions. Journal of Child Psychology and Psychiatry, 44, 134-151. 
Table 1

Mean Confederate Behaviors by Condition

Behavior

\begin{tabular}{|c|c|c|c|c|c|c|c|c|c|}
\hline Condition & Criticism & Command & Interruption & Ignore & Takeover & $\begin{array}{c}\text { Praise } \\
\text { Participant }\end{array}$ & $\begin{array}{c}\text { Praise } \\
\text { Dyad }\end{array}$ & Laughter & Encourage \\
\hline $\begin{array}{l}\text { Warm- } \\
\text { responsive } \\
\text { Critical- } \\
\text { controlling }\end{array}$ & $\begin{array}{l}0 \\
5.6\end{array}$ & 3.8 & 2.2 & 2.4 & 0 & 7 & 5.2 & 1.4 & 5.2 \\
\hline
\end{tabular}


Table 2

Mean Participant Self-reported Post-task Questionnaire Ratings By Condition

\begin{tabular}{|c|c|c|}
\hline \multirow[b]{2}{*}{ Post-task Question } & \multicolumn{2}{|c|}{ Condition } \\
\hline & Critical-Controlling $(n=25)$ & Warm-Responsive $(n=22)$ \\
\hline \multicolumn{3}{|l|}{ Felt Anxious } \\
\hline$M$ & 2.12 & 1.23 \\
\hline$S D$ & 1.01 & .43 \\
\hline \multicolumn{3}{|l|}{ Felt Frustrated } \\
\hline$M$ & 1.68 & 1.05 \\
\hline$S D$ & .80 & .21 \\
\hline \multicolumn{3}{|l|}{ Felt Judged } \\
\hline$M$ & 2.76 & 1.18 \\
\hline$S D$ & 1.30 & .66 \\
\hline \multicolumn{3}{|l|}{ Liked My Partner } \\
\hline$M$ & 3.08 & 4.55 \\
\hline$S D$ & .86 & .60 \\
\hline \multicolumn{3}{|c|}{ Like to Interact Social } \\
\hline$M$ & 2.32 & 4.09 \\
\hline$S D$ & .85 & .75 \\
\hline \multicolumn{3}{|l|}{ Like to Interact Work } \\
\hline$M$ & 2.80 & 4.55 \\
\hline$S D$ & 1.08 & .60 \\
\hline
\end{tabular}


Table 3

Correlation Coefficients for Self-reported Participant Post-task Questionnaire Ratings

\begin{tabular}{|c|c|c|c|c|c|c|}
\hline Question & 1 & 2 & 3 & 4 & 5 & 6 \\
\hline 1. Felt Anxious & --- & & & & & \\
\hline 2. Felt Frustrated & $.51 * *$ & --- & & & & \\
\hline 3. Felt Judged & $.63^{* *}$ & $.63 * *$ & --- & & & \\
\hline 4. Liked my partner & $-.53 * *$ & $-.36^{*}$ & $-.57 * *$ & --- & & \\
\hline $\begin{array}{l}\text { 5. Like to interact } \\
\text { social }\end{array}$ & $-.66 * *$ & $-.45 * *$ & $-.66 * *$ & $.77 * *$ & --- & \\
\hline $\begin{array}{l}\text { 6. Like to interact } \\
\text { work }\end{array}$ & $-.66 * *$ & $-.44 * *$ & $-.66 * *$ & $.77 * *$ & $.86^{* *}$ & --- \\
\hline
\end{tabular}

Note. ${ }^{*} \mathrm{p}<.05 . * * \mathrm{p}<.01{ }^{* * *} \mathrm{p}<.001$. 
Table 4

Follow-up Univariate Analyses of Variance for Post-task Questionnaire

\begin{tabular}{lcccccc}
\hline Variable & & \multicolumn{2}{c}{ Like } \\
& Anxious & Frustrated & Judged & Partner & Interact Social & Interact Work \\
\hline Condition & & & & & & \\
\hline
\end{tabular}

Note. ${ }^{* *} p<.01 .{ }^{* * *} p<.001$. 
Table 5

Mean Observer Behavior Ratings By Participant Condition

\begin{tabular}{|c|c|c|}
\hline \multirow[b]{2}{*}{ Participant Behavior } & \multicolumn{2}{|c|}{ Condition } \\
\hline & Critical-Controlling $(n=25)$ & Warm-Responsive $(n=22)$ \\
\hline \multicolumn{3}{|l|}{ Criticism Dyad } \\
\hline$M$ & .44 & .82 \\
\hline$S D$ & .82 & 1.05 \\
\hline \multicolumn{3}{|l|}{ Criticism Self } \\
\hline$M$ & 1.16 & .41 \\
\hline$S D$ & 1.38 & .59 \\
\hline \multicolumn{3}{|l|}{ Praise Dyad } \\
\hline$M$ & .08 & .82 \\
\hline$S D$ & .28 & 1.10 \\
\hline \multicolumn{3}{|l|}{ Praise Confederate } \\
\hline$M$ & .52 & .18 \\
\hline$S D$ & 1.01 & .50 \\
\hline \multicolumn{3}{|l|}{ Withdrawal } \\
\hline$M$ & 17.20 & 12.23 \\
\hline$S D$ & 9.83 & 11.67 \\
\hline \multicolumn{3}{|l|}{ Ignore } \\
\hline$M$ & .08 & .09 \\
\hline$S D$ & .28 & .29 \\
\hline \multicolumn{3}{|l|}{ Respond Positively } \\
\hline$M$ & 9.64 & 14.64 \\
\hline$S D$ & 6.18 & 6.44 \\
\hline
\end{tabular}


Table 6

Correlation Coefficients for Observer Behavior Ratings

\begin{tabular}{|c|c|c|c|c|c|c|c|}
\hline Behavior & 1 & 2 & 3 & 4 & 5 & 6 & 7 \\
\hline 1. Criticism Dyad & --- & & & & & & \\
\hline 2. Criticism Self & -.07 & --- & & & & & \\
\hline 3. Praise Dyad & .13 & .00 & --- & & & & \\
\hline $\begin{array}{l}\text { 4. Praise } \\
\text { Confederate }\end{array}$ & .16 & .29 & .09 & --- & & & \\
\hline 5. Withdrawal & -.23 & -.17 & $-.30 *$ & -.16 & --- & & \\
\hline 6. Ignore & -.12 & -.08 & -.06 & -.14 & -.07 & --- & \\
\hline $\begin{array}{l}\text { 7. Respond } \\
\text { Positively }\end{array}$ & .23 & -.22 & $.31 *$ & -.11 & $-.36^{*}$ & -.16 & --- \\
\hline
\end{tabular}

Note. ${ }^{*} \mathrm{p}<.05$. 
Table 7

Follow-up Univariate Analyses of Variance for Observer Ratings of Participant Behaviors

\begin{tabular}{|c|c|c|c|c|c|c|c|}
\hline \multirow[b]{2}{*}{ Variable } & \multicolumn{7}{|c|}{ ANOVA $F(1,45)$} \\
\hline & $\begin{array}{l}\text { Criticism } \\
\text { Dyad }\end{array}$ & $\begin{array}{l}\text { Criticism } \\
\text { Self }\end{array}$ & $\begin{array}{l}\text { Praise } \\
\text { Dyad }\end{array}$ & $\begin{array}{c}\text { Praise } \\
\text { Confederate }\end{array}$ & Withdrawal & Ignore & Respond Positively \\
\hline Condition & 1.91 & $5.64 *$ & $10.58 * *$ & 2.04 & 2.52 & 0.02 & $7.36 * *$ \\
\hline
\end{tabular}




\section{Appendix A}

\section{Coded Participant Behavior}

Behavior Operational Definition

Withdrawal from task

Criticism-Self

Criticism-Dyad

Criticism-Confederate

Ignore confederate statement

Respond positively to confederate

Encouragement
Does not touch task materials or make any statements for 5 or more seconds.

Comment that conveys a negative selfappraisal (e.g., “My fold doesn't look very good.")

Comment that conveys negative appraisal of dyad (e.g., "We're not doing very well at this.").

Comment that conveys a negative appraisal of confederate (e.g., "You aren't doing that right.").

Remains silent after confederate question or statement for at least 3 seconds.

Respond to question or statement within 3 seconds.

Comment that conveys that participant/dyad will succeed at task (e.g., "We can do this."). 


\begin{tabular}{|c|c|}
\hline Behavior & Operational Definition \\
\hline Praise-Self & $\begin{array}{l}\text { Comment that conveys a positive self- } \\
\text { appraisal (e.g., "My folds are really neat.") }\end{array}$ \\
\hline Praise-Dyad & $\begin{array}{l}\text { Comment that conveys a positive appraisal } \\
\text { of dyad (e.g., "We're doing really well at } \\
\text { this.") }\end{array}$ \\
\hline Praise-Confederate & $\begin{array}{l}\text { Comment that conveys a positive appraisal } \\
\text { of the confederate (e.g., "You're doing } \\
\text { really well making this.") }\end{array}$ \\
\hline Verbal Interruption & Begins talking while confederate is talking. \\
\hline Physical takeover of task. & $\begin{array}{l}\text { Removes origami or instruction sheet from } \\
\text { confederate's hands. }\end{array}$ \\
\hline Positive command & $\begin{array}{l}\text { Gives command stating what to do (e.g., } \\
\text { "Fold the paper like this.") }\end{array}$ \\
\hline Negative command & $\begin{array}{l}\text { Gives command stating what not to do } \\
\text { (e.g., "Don't fold the paper like that.") }\end{array}$ \\
\hline Nervous laughter & Laughs in a way that conveys anxiety. \\
\hline Appropriate laughter & Laughs in response to shared humor. \\
\hline Speech NOC & Speech not otherwise coded \\
\hline
\end{tabular}


Appendix B

Demographic Questionnaire

Participant ID Number:

Date:

1. Your age:

2. What is your gender? Please circle one.
a. Male
b. Female

3. What is your year in school? Please circle one.
a. Freshman
b. Sophomore
c. Junior
d. Senior

4. With which racial background do you identify? Please circle as many as apply to you.
a. White/Caucasian
b. African American
c. Asian American
d. Native American/Pacific Islander
e. Other: (please fill in blank)

5. With which ethnic background do you identify? Please circle one.
a. Hispanic
b. Non-Hispanic 
Appendix C

Post-Task Questionnaire

Participant ID Number:

Date:

Please complete the following questions concerning how you felt while completing the origami figures with your partner by circling one number for each of the questions. Your dyad partner will not see these responses.

1. I felt anxious or uncomfortable while working with my partner.
1
2
3
4
5
Not at all
Somewhat
Very Much

2. I felt angry or frustrated while working with my partner.
1
2
3
4
5
Not at all
Somewhat
Very Much

3. I felt like my partner was judging me and my skill at making the origami figures.

$\begin{array}{ccccc}1 & 2 & 3 & 4 & 5 \\ \text { Not at all } & & \text { Somewhat } & & \text { Very Much }\end{array}$

4. I liked my partner.
12
3
4
5
Not at all
Somewhat
Very Much

5. I would like to interact with my partner again in a social situation.
1
2
3
4
5
Not at all
Somewhat
Very Much

6. I would like to interact with my partner again in a work situation (e.g., at a job or on a school project).

$\begin{array}{ccccc}1 & 2 & 3 & 4 & 5 \\ \text { Not at all } & & \text { Somewhat } & & \text { Very Much }\end{array}$


Appendix D

Coded Confederate Behaviors

Table D1

Critical-Controlling Confederate Behaviors

Behavior

Operational Definition

Minimum Frequency

Criticism-Participant

Make a comment that

5

conveys negative appraisal of

participant/participant's

performance on task.

Negatively-stated Command Give instruction to participant

by telling them what not to

do.

Verbal interruption

Begin talking while

participant is talking.

Ignore participant statement Remain silent after

participant question or

statement for at least 3

seconds.

Physical takeover of task

Remove origami paper or

1

instruction sheet from

participant's hands.

Note: Minimum frequency indicates the number of times the confederate must perform the behavior during the 10-minute interaction. 
Table D2

Warm-Responsive Confederate Behaviors

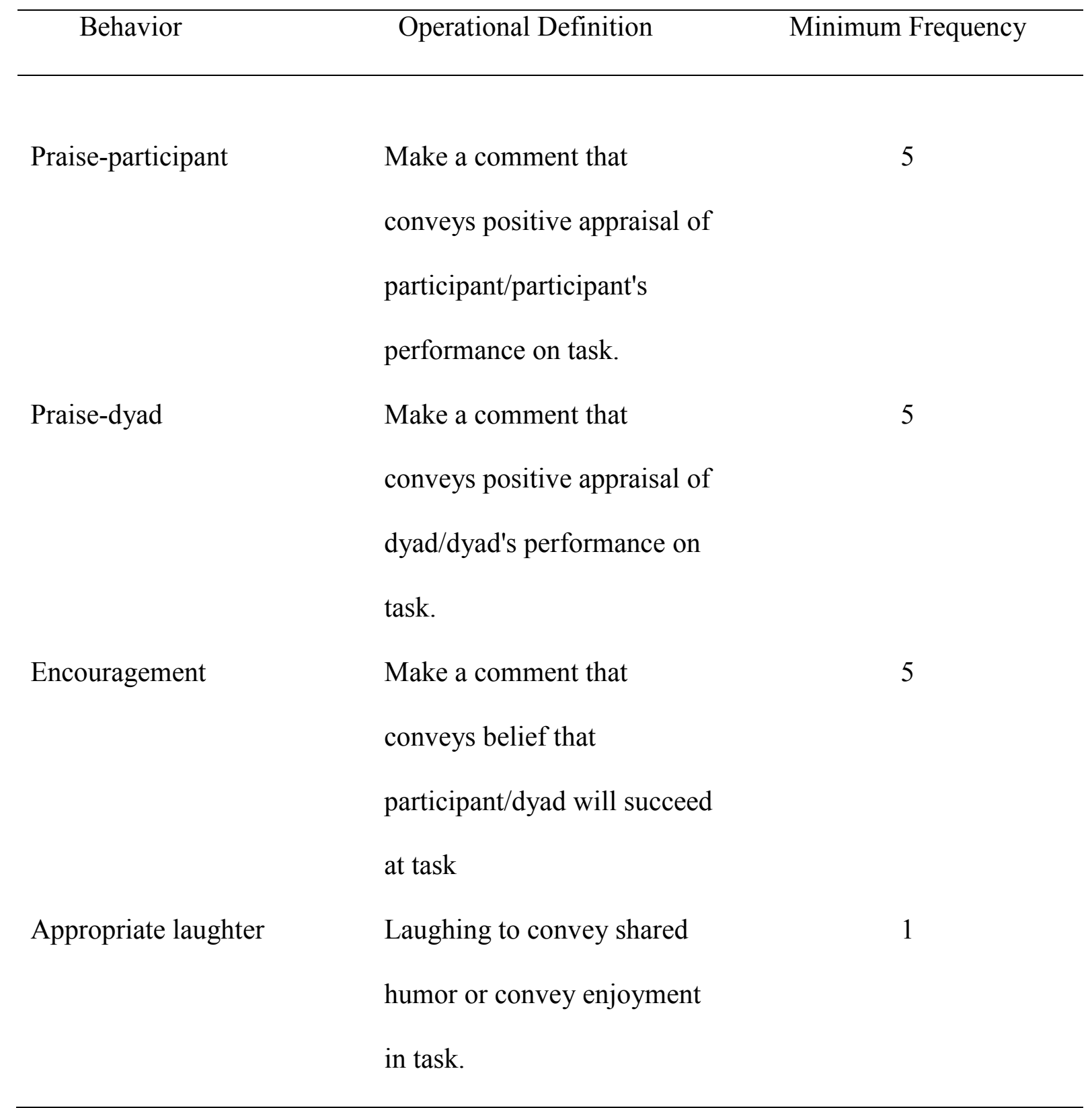

Note: Minimum frequency indicates the number of times the confederate must perform the behavior during the 10-minute interaction. 


\section{Appendix E}

Origami Instructions

Origami instructions (to be read out loud):

"Have any of you heard of origami before? Well, today you will work together on creating two origami figures; here is one of the figures you will be asked to make (show penguin figure)."

"Just to give you a little background. . .Origami is an ancient art of paper folding. The word origami is Japanese and comes from the words "ori" (which means "to fold") and "kami" (which means "paper").

"Each figure requires the use of only one piece of paper; however, you will have a total of four sheets in case you make a mistake. Here is a set of instructions for you to share (hold up instructions, but do not give to participants yet). This page demonstrates the "Outside Reverse Fold." Hold up the sheet that explains the "Outside Reverse Fold." You will need to look at this page when making the figures.

You will be given ten minutes to complete both figures. Please work together. Start with the penguin figure and, if you have time, move on to the Swan. Do you have any questions?" (Answer any questions).

"Okay, I'm going to leave the room so you can work on this together. As soon as I leave, you may begin working on the penguin!" Set instructions on the CENTER of the table, go into the observation room, and begin timing 